\title{
Congenital bile acid synthesis defect type 1
}

INSERM

\section{Source}

INSERM. (1999). Orphanet: an online rare disease and orphan drug data base. Congenital bile acid synthesis defect type 1. ORPHA:79301

Congenital bile acid synthesis defect type 1 (BAS defect type 1) is the most common anomaly of bile acid synthesis (see this term) characterized by variable manifestations of progressive cholestatic liver disease, and fat malabsorption. 